\title{
Gênero, reciprocidade e mercado no cuidado de idosos
}

\author{
Anna Bárbara Araujo
}

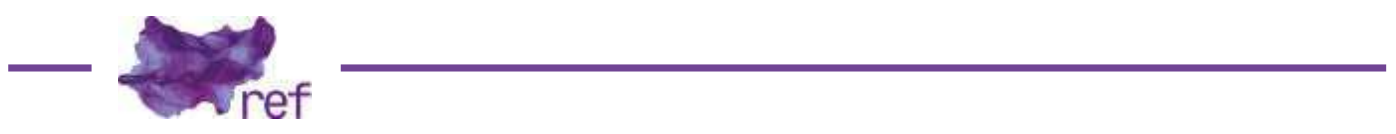

Resumo: Este texto discute o tema do trabalho das cuidadoras de idosos que têm seus serviços agenciados por uma empresa de cuidado, com base num estudo de caso no centro da cidade do Rio de Janeiro. O trabalho dessas mulheres é analisado a partir da tensão entre duas lógicas: uma que prevê o cuidado plasmado por valores associados à reciprocidade e solidariedade, tidos como femininos, e outra marcada pela necessidade de profissionalização e de controle dos sentimentos. Os resultados da pesquisa sugerem que as duas lógicas - a da reciprocidade e a do mercado - competem na produção de demandas morais e emocionais do trabalho de cuidado, e que algumas cuidadoras operam estratégias de distanciamento do modelo familiar do cuidado de modo a valorizar seu próprio trabalho. Palavras-chove: cuidado; gênero; demandas emocionais do trabalho; reciprocidade

\section{Gender, Reciprocity and Market in Elderly Care}

Abstract: This text discusses the theme of care workers for the elderly who have their services intermediated by a care enterprise. The text is based on a case study in Rio de Janeiro. These women's work is analyzed through the tension between two logics: one that sees care shaped by values associated with reciprocity and solidarity, perceived as feminine, and another marked by the necessity of professionalization and emotion's management. The research's results suggest that both logics - the reciprocity one and the market one - compete in the production of care work's moral and emotional demands, and that some care workers operate strategies of detachment from the family model of care as a way to value their own work.

Keywords: Care; Gender; Work's Emotional Demands; Reciprocity

\section{Introdução}

O presente texto se debruça sobre o trabalho das cuidadoras que têm seus serviços oferecidos por empresas no que diz respeito à tensão entre, de um lado, as exigências de formalização e profissionalização do cuidado e, de outro, o caráter ativo, por parte da empresa, na construção da imagem das cuidadoras enquanto empreendedoras de valores associados à reciprocidade e à família, como amor, paciência e sacrifício'.

Para esta compreensão, é importante considerar que o trabalho das mulheres reconstrói noções de feminilidade, de masculinidade e de (hetero)sexualidade (Chandra MOHANTY, 1997) ainda que essas variem de acordo com o contexto sócio-histórico ao qual se vinculam - de modo que me interessa compreender as ideologias que fundamentam $o$ trabalho das mulheres ao mesmo tempo em que se analisa o modo pelo qual o mesmo é desvalorizado justamente por sua associação com o feminino e com a relação entre mulher e família.

A noção de ideologia é bastante polissêmica na teoria sociológica. A despeito disso, aqui ela é mobilizada a partir principalmente da contribuição de teóricas pós-coloniais como Mohanty (1997) e Gayatri Chakravorty Spivak (1982, p. 259). Dessa forma, entendo ideologias como categorias

\footnotetext{
${ }^{1}$ Agradeço a Bila Sorj, Fernando Rabossi e às pareceristas anônimas pelas sugestões e críticas recebidas em versões
} anteriores deste texto. 
classificatórias - ou conjuntos de categorias - que organizam e orientam a ação prática. São, sobretudo, construções práticas e discursivas sobre as relações sociais que um grupo toma como autoevidentes ou naturais, às quais se nega qualquer sedimentação histórica ${ }^{2}$. No texto, a categoria de ideologia, ou construção ideológica, ajuda a compreender a categoria de reciprocidade, conforme será explicitado na próxima seção. Está fora do escopo deste artigo, no entanto, investigar as bases genealógicas da reciprocidade enquanto ideologia, de modo que me atentarei aos efeitos dessa.

Já a noção de divisão sexual do trabalho, conforme discutida especialmente pelas teóricas do feminismo materialista francês, permite analisar como a divisão do trabalho entre homens e mulheres é organizada através de dois princípios, conforme argumentam Helena Hirata e Danièle Kergoat (2007): 1) o princípio da separação (existem trabalhos de mulher e trabalhos de homem) e; 2) o princípio da hierarquização (o trabalho do homem tem mais valor que o trabalho da mulher). Deve-se pontuar que as configurações específicas assumidas por esta forma de divisão social do trabalho variam enormemente ao longo do tempo e dos espaços. Mas pode-se dizer que muitos dos trabalhos tidos como femininos são considerados, em alguma medida, enquanto realização daquilo que é construído sócio-historicamente como essencial e natural à mulher. Isso implica, muitas vezes, que os papéis sociais atribuídos às mulheres sejam simbolizados enquanto derivações diretas de sua função procriativa e maternal (Sherry ORTNER, 1979). Assim, cria-se a ideia de que a mulher seria uma cuidadora natural, cujo dever repousaria na proteção da família e na manutenção de seu bem-estar.

Também é necessário dizer que o ponto de partida deste texto reside na observação das transformações do mercado de trabalho verificadas no país desde os anos 2000 , onde cresce expressivamente o trabalho intermediado (Nadya Araujo GUIMARÃES, 2011). Trabalho intermediado é definido como a triangulação da oferta de postos de trabalho, na medida em que um agente, em geral uma empresa, se coloca entre os trabalhadores que demandam emprego e os ofertantes do posto de trabalho, disponibilizando as vagas e encaminhando o trabalhador ao posto de trabalho (GUIMARÃES, 2009). Cabe notar que o trabalho intermediado não se resume à terceirização, já que muitas vezes não se estabelece uma relação de trabalho entre a empresa intermediária e o trabalhador.

A pesquisa se deu em uma empresa localizada na cidade do Rio de Janeiro, com um quadro de 6000 cuidadoras cadastradas até o momento da pesquisa. Essa consistiu no acompanhamento da rotina da empresa durante um mês e da realização de 45 entrevistas com as cuidadoras. A duração das entrevistas variou entre 20 minutos e 1 hora e 30 minutos.

A empresa pesquisada é responsável por capacitar as cuidadoras através de cursos de formação e encaminhá-las ao mercado de trabalho, constituindo-se, assim, em uma empresa de trabalho intermediado. Nesse contexto, a empresa funciona como um agente disciplinador do trabalho em que a própria inserção no mercado de trabalho é a moeda de negociação. É, portanto, uma situação diferente, em termos hierárquicos e de organização do trabalho, do que ocorre com as cuidadoras autônomas, que se inserem no mercado de trabalho a partir de laços de amizade e vizinhança, e que se reportam diretamente à família do idoso e suas regras específicas e mais ou menos contextuais.

Assim, tomando como norte analítico as reflexões sobre a divisão sexual do trabalho e o conceito de trabalho intermediado, o texto se divide da seguinte forma:

Inicialmente, discutirei como a análise das demandas morais e emocionais é útil para compreender o trabalho de cuidado em sua dimensão generificada. Em seguida, mostrarei como as diferentes modulações destes preceitos morais e emocionais variam conforme a socialização profissional e a trajetória de vida da cuidadora. Por fim, discuto brevemente as implicações que a análise das demandas morais e emocionais têm sobre o debate entre mercado e reciprocidade, e o modo como esse pode ser entendido no caso específico das cuidadoras, e no das trabalhadoras de modo geral.

\section{A reciprocidade como ícone: a produção de demandas morais e emocionais do trabalho de cuidado}

Vários autores (cf. Anne-Marie DEVREUX, 2005; ORTNER, 1979; Rosemary CROMPTON, 2006; François de SINGLY, 2007) têm ressaltado como o trabalho reprodutivo, isto é, aquele que assegura a continuidade das pessoas e da vida, como o cuidado de idosos, por exemplo, tem sido historicamente atribuído às mulheres, que o exercem na privacidade do mundo familiar, de maneira não remunerada. Quando remunerado, esse trabalho continua a ser exercido por mulheres. Desse modo, importa considerar em que medida o modelo de cuidado familiar generificado mostra-se presente uma vez que o cuidado passa a ser mercantilizado.

${ }^{2}$ A partir desta definição, a noção de ideologia se aproxima das reflexões realizadas por Pierre Bourdieu (2007) sobre razão mítica e arbitrário histórico. 
Assim, buscarei analisar o trabalho do cuidado - a partir de alguns traços específicos considerando sua condição de embeddedness ${ }^{3}$ (Karl POLANYI, 1957), ou seja, sua interação com instituições e estruturas sociais, econômicas e não econômicas, em especial a estrutura de gênero. Em outras palavras, procurarei analisar como as normas de feminilidade que orientam o cuidado familiar são agenciadas pela dinâmica do cuidado remunerado, ou como os ideais de reciprocidade e de solidariedade femininos são operados e transformados pelo mercado, tornandose demandas morais e emocionais do trabalho das cuidadoras.

Ou seja, me interessa analisar as relações de força que acabam por definir e tensionar a prática do cuidado por intermédio da produção - e do manejo - da ambivalência entre o que chamo aqui de reciprocidade e mercado. Em outras palavras: como o trabalho não remunerado, o sacrifício das mulheres na família, o cuidado intergeracional e a vida íntima - ícones culturais da reciprocidade - são mobilizados e transformados pela lógica do mercado.

Cabe notar que a tensão entre reciprocidade e mercado parece ser própria aos trabalhos onde as mulheres são maioria ${ }^{4}$, mas o modo pelo qual ela se concretiza varia conforme o contexto. Mohanty (1997), por exemplo, mostra como a construção discursiva da mulher como dona de casa na Índia afeta negativamente as mulheres trabalhadoras domiciliares da indústria têxtil, invisibilizando seu trabalho e dificultando suas estratégias de organização coletiva. Neste caso, a obrigação moral de pertença ao mundo das reciprocidades familiares tem por efeito um apagamento, no plano das identidades pessoais e coletivas, da participação no mundo do mercado de trabalho remunerado.

Minha aposta é que a análise das demandas morais e emocionais do trabalho pode ser útil para capturar essa tensão em seus diversos arranjos possíveis, mas, para os fins deste texto, lidarei exclusivamente com o caso das cuidadoras. Cabe afirmar que as demandas morais e emocionais de cuidado se relacionam antes com uma idealização dos papéis femininos de cuidado não pago (consolidados através de ideais de altruísmo, de afetividade e de atenção) do que com as relações concretas e situações práticas onde se desenvolvem as atividades de cuidado (na família e no mercado). Ou seja, a despeito da normalização operada pelos papéis femininos de cuidado, há espaço - tanto no cuidado não pago quanto no cuidado pago - para desacordos, conflitos e violências, ainda que sejam considerados moralmente condenáveis e vistos como um desajuste. É relevante, portanto, especificar o que estou chamando de reciprocidades no modelo de cuidado familiar e nos papéis femininos de cuidado.

A reciprocidade, segundo o argumento de Eric Sabourin (2008), pode ser entendida como um sentimento ou um impulso de preocupação com o outro que tende a se traduzir em obrigações para com o mesmo. Para a compreensão da reciprocidade, segundo esse autor, considerar a temporalidade é fundamental. Assim, essa pode se realizar através de dádivas e contradádivas entre pessoas ou grupos, mas pode também se manifestar de forma indireta, através da circulação de bens (materiais e simbólicos) entre as gerações. No fim do Ensaio sobre a Dádiva, Marcel Mauss (2003 [1925]) cita a previdência social como uma das feições modernas da dádiva, na medida em que esta prevê a solidariedade generalizada, mediada pelo Estado, entre grupos de idade diferenciada para seu funcionamento. Embora Mauss não utilize a nomenclatura de reciprocidade indireta, pode-se entender o fenômeno citado como um exemplo desta.

Meu argumento é de que a noção de reciprocidade indireta fundamenta o trabalho de cuidado nas famílias e no mercado. Em termos bastante esquemáticos, pode-se pensar no exemplo da filha que cuida de sua mãe já idosa, que por sua vez já cuidou dela quando pequena, ou da cuidadora que relata cuidar de um idoso como se ele fosse de sua própria família - no que diz respeito à construção de vínculos emocionais e do senso de obrigação - ou seja, como se tratasse de uma contradádiva. Ou, ainda, a cuidadora profissional relata cuidar como gostaria de ser cuidada em sua própria velhice. Nesse caso, opera uma aposta de reciprocidade, orientada para o futuro, como fica claro neste trecho de entrevista, que é representativo das falas de outras cuidadoras quando indagadas sobre o que esperam de seu próprio envelhecimento. Em geral, relatam sua preferência pelo cuidado familiar e não institucionalizado:

Eu quero um tratamento igual o que eu dou pra eles. Peço a Deus que meus filhos cuidem bem de mim. Porque eu cuido bem deles pra isso e cuido das outras pessoas também pra isso. Eu já falei pra eles: "cuida de mim, hein, não me bota no asilo não, quero ficar juntinho de vocês até o último dia da minha vida". (Cuidadora Mariana)

Ou seja, o cuidado seria animado pelas reciprocidades intergeracionais cujo modelo, no caso do cuidado, é a família. Não obstante, importa considerar que a reciprocidade indireta do cuidado é generificada. São as mulheres que se ocupam do cuidado, e a atividade dessas

${ }^{3}$ O termo é traduzido por diferentes autores como imbricação, incrustação ou integração. Em razão dessa multiplicidade, opto por utilizar o termo no original.

${ }^{4}$ Isso porque há uma tendência em associar o trabalho remunerado das mulheres enquanto continuidade do trabalho realizado por elas na família. Essa continuidade muitas vezes é construída a partir da associação entre o feminino e atividades de cuidado (Lee BADGETT; Nancy FOLBRE, 1999). 
mulheres enquanto cuidadoras profissionais e familiares é pressuposta nas narrativas sobre a importância do cuidado para a manutenção das solidariedades entre grupos de idades distintas. Assim, quando pensada em termos indiretos ou intergeracionais e em sua feição generificada, a noção de reciprocidade passa a ser compatível com a noção de sacrifício. Ou, ainda, passa a ser utilizada discursivamente como forma de mitigar a ideia de que o cuidado, da forma como está estruturado atualmente, exige de fato um grande sacrifício para sua realização e não se trata apenas de mera troca-dádiva.

Ou seja, o cuidado que muitas vezes envolve trabalho pesado, difícil e emocionalmente demandante, como mostrarei a seguir, pode ser justificado pela expectativa de recebimento do cuidado no futuro, ser pensado como parte da obrigação estabelecida com as gerações anteriores ou, ainda, ser tomado enquanto componente de uma linguagem que privilegia a construção de vínculos emocionais positivos nas relações familiares. Em outras palavras, proponho que a noção de reciprocidade, tal como presente nas narrativas das cuidadoras ${ }^{5}$, pode ser compreendida como parte de uma construção ideológica que tem por efeito a justificação da divisão sexual do trabalho ${ }^{6}$. Isso implica considerar que a reciprocidade opera, neste caso, prioritariamente no plano representacional.

Ao utilizar tal definição de reciprocidade, meu objetivo não é rejeitar qualquer possibilidade de existência de relações interpessoais significativas e de vínculos emocionais positivos e recíprocos entre cuidadoras e idosos. Inclusive tais vínculos são mencionados pelas cuidadoras. Não obstante, opto por enfatizar como uma específica construção discursiva sobre as relações familiares que privilegia a noção de reciprocidade indireta orienta - e tem efeitos sobre - o trabalho das cuidadoras, a partir da valorização e prescrição de determinados sentimentos e tipos de relações, como mostrarei a seguir. Dessa forma, ao utilizar as noções de reciprocidades e solidariedades familiares ao longo do texto, estarei me referindo a essa construção.

\section{Moralidade e emoções como demandas do trabalho}

Então, a primeira coisa é a pessoa gostar de servir, né. Gostar de cuidar. E ter muita paciência. E a gente tenta avaliar na hora da entrevista, a gente tenta esmiuçar isso pra ver se ela tem o perfil ou não. Mas a gente não tem como saber, a gente sempre busca na última referência dela de trabalho. O departamento de checagem liga pra saber se ela foi uma boa funcionária, se ela era paciente, né, tudo isso. Eu acho que o principal é ela gostar e saber, mas não é qualquer um né, que pode ser cuidador de idoso, tem um monte de gente que faz o curso aqui que a gente vê que não tem perfil nenhum, sabe. $E$ às vezes a pessoa quer ganhar muito $e$ trabalhar pouco, sabe, não quer se sacrificar, porque é um sacrifício que você faz, sair de casa, né, pra ir trabalhar dessa forma todos os dias. Saber que tem que aguentar muito idoso falando besteira, muita família falando besteira e tem muita gente que não tem sabe, essa capacidade de tá aguentando. Manter esse equilíbrio, né. Então a gente tenta avaliar de todas as formas aqui. Desse jeito. (Diretora da empresa MaisCuidador).

O trecho acima mencionado foi extraído de uma entrevista com a diretora da empresa onde foi realizada a pesquisa; mais especificamente, foi a resposta para a pergunta "o que é necessário para ser uma boa cuidadora?". Desse relato, tomo três noções mobilizadas pela diretora como fundamentais para entender o gabarito moral e emocional que informa $\circ$ trabalho de cuidado, quais sejam: o apreço pelo próprio trabalho (ou amor), a paciência e o sacrifício.

Antes de me debruçar mais detidamente sobre essas noções, cabe aqui discutir brevemente que lugar elas têm neste texto e no modo como entendo o trabalho de cuidado. Minha hipótese é de que essas noções são mais do que meras qualidades das boas cuidadoras - elas o são também, mas além disso - se constituem como demandas do trabalho, na medida em que: 1) espera-se que as cuidadoras tenham tais qualidades; 2) essas qualidades tornam-se parte do trabalho e, como tal, participam do processo de (des)valorização do mesmo; 3) são sujeitas ao controle dos empregadores.

Aqui, opto por utilizar a categoria de demandas morais e emocionais do trabalho, ao invés da célebre noção de trabalho emocional (Arlie HOCHSCHILD, 2003 [1983]) que foi desenvolvida a partir de um estudo sobre o trabalho de comissárias de bordo da Delta Airlines nos Estados Unidos. Hochschild descobriu que, para essas trabalhadoras, ser amigável, sorrir e acalmar passageiros irritados era tão central ao seu trabalho como lhes servir comida ou apresentar as instruções de segurança. Dessa forma, a noção denota o gerenciamento das emoções das trabalhadoras, especialmente no setor de serviços. Este se apresenta como um estilo emocional de oferecer o serviço e, nesse sentido é, segundo a autora, parte de seu trabalho remunerado e, portanto, sujeito à alienação e à mercantilização.

\footnotetext{
${ }^{5}$ Mas que se estende para além dessas, na medida em que pode justificar o ideal de domesticidade feminina.

${ }^{6}$ Em razão da minha escolha em enfatizar a reciprocidade como parte da divisão sexual do trabalho, julgo me distanciar das reflexões sobre a dádiva empreendidas por autoras feministas como Marilyn Strathern (2006) e Arlie Hochschild (2013), ao mesmo tempo em que tendo a me aproximar teoricamente de proposições clássicas como a de Gayle Rubin (1993). Por motivos de espaço, não poderei expandir esta discussão.
} 
Defendo que o termo demandas morais e emocionais do trabalho deixa mais claro o caráter simultâneo de imposição e de prescrição pelo qual as emoções e moralidades são organizadas e tornadas parte do trabalho. Isto é, falar em demandas implica lançar luz sobre os processos de produção, assimilação e consumo das mesmas. Ou seja, me permite discutir transversalmente: 1) como essas demandas se estruturam a partir das relações de gênero e das dinâmicas do mercado de trabalho, e mais especificamente, das empresas de cuidado; 2) como são incorporadas pelas cuidadoras e que tipo de agência elas têm sobre essas demandas e; 3 ) como se fazem sentir nas interações cotidianas com os idosos.

Além disso, Hochschild está preocupada em mostrar como as comissárias de bordo representam um papel para os passageiros, inclusive mostrando os efeitos perversos dessa representação sobre sua vida fora do trabalho. É notável, por exemplo, o caso mencionado pela autora da comissária que, após um dia longo de voo, não consegue se desvencilhar de seu estado efusivo, comunicativo e acelerado e sofre com isso. Em outros trabalhos, no entanto, como defende Nicolas Wasser (2017, p. 128), a mercantilização dos sentimentos diz mais respeito ao trabalhador "ser" e habitar um papel - para continuar com a metáfora teatral de Hochschild - do que efetivamente representá-lo. Esse parece ser o caso das cuidadoras, de modo que a noção de demandas morais e emocionais permite discutir as diferentes maneiras como essas trabalhadoras habitam seu papel, ao abraçar ativa e diferencialmente as demandas morais e emocionais que são parte de seu trabalho. Isso não significa que não haja sofrimento ou alienação em seu trabalho, mas que esses são potencialmente de natureza diferente daqueles apontados por Hochschild. Ou seja, dizem menos respeito ao desvencilhamento do papel do que às exigências específicas do próprio papel.

Além disso, cabe afirmar, retomando o argumento de Alvin Gouldner (1960), que a norma de reciprocidade por vezes é usada de modo a justificar, motivar ou ainda propulsionar demandas concretas oriundas de obrigações de status. Esse parece ser o caso encontrado na pesquisa (embora não seja possível explicá-lo em sua totalidade por este único mecanismo), conforme buscarei argumentar a seguir.

\section{O amor}

1) A última que eu cuidei, ela me chamou de mãe. Da última vez que ela falou, ela me chamou de mãe. E aquilo, nossa... pra mim. Seis meses trabalhando com ela, tá entendendo? Ela fazia todo tipo de arte do mundo. No dia que ela me chamou de mãe ela nunca mais falou. Mas me reconheceu como mãe até o último momento (...) Então assim, eu era tudo pra ela. De chegar a outra cuidadora e ela ficar 3 dias sem tomar banho. (...) Ela tava suja. Fui lá, limpei ela toda, então assim, a gente passa a ter como filho mesmo. (Cuidadora Rita).

2) Ah, então, primeiro você tem que amar. Amar o ser humano. Por quê? Porque tem muitos idosos... a vida toda carregam características que são só deles. Então uns ficam mais chatos, outros ficam menos. E você amando, você aprende a respeitar o limite do idoso. Lá onde eu tô, por exemplo, tem idosos difíceis de se lidar. Então se você não tem o amor, nem tenta. Outra coisa, se você for fazer pelo dinheiro também, nem tenta. Porque ver o ser humano simplesmente como uma troca financeira, não tem como, você tem que amar. (Cuidadora Mariana).

3) A maioria dos meus pacientes, ele já não fala mais. Ele se expressa muito pouco. Então o meu amor se resume - se resume é força de expressão - é o cuidar dele. Mantê-lo sempre limpo, fez xixi, troca logo. Fez cocô, troca logo. Mudança de decúbito, pra não dar escara. Deu banho, passa um hidratante, passa um Dersani pra ter alívio na pele. Procurar botar sentado pra descansar porque o idoso deitado ele tem acúmulo de líquido no pulmão e aí pode dar pneumonia. Então bota ele sentado pra ver a mudança da situação de deitar, pro sentar. Faz um... é um bem-estar pra ele. Muito bom, tá, então quando ele ver que tem... sentir que tem uma outra posição de conforto. Dar comida direita. Dar uma boa comida, que a maioria é tudo comida batida no liquidificador, né? Só vai as proteínas. Mas tentar dar uma comida fresca, feita no dia. E não aquela que faz na segunda pra ficar a semana toda. Não. Faz todo dia. Nem que seja almoço e janta. Lá a gente faz assim. Faz uma sopa que vai pro almoço e pra janta. No outro dia, a mesma coisa. Vitamina faz na hora, porque além de ser uma coisa fresca, as frutas perdem a proteína dela, as vitaminas dela. (...) Esse é o nosso amor, esse é o nosso cuidado, esse é o nosso carinho. (Cuidadora Nara).

Acima foram mencionadas três diferentes narrativas sobre a importância do amor para o trabalho das cuidadoras. Nas falas das cuidadoras, o apreço pelo próprio trabalho se confunde com gostar do idoso de quem se cuida e, por isso, trato as duas situações sem separá-las.

Cabe dizer que, em alguma medida, essas narrativas se interpõem, se interconectam e se cruzam, mas como recurso heurístico cabe analisá-las aqui separadamente. Trato-as aqui como modulações ou variantes de uma mesma matriz, qual seja, o amor como demanda moral e emocional no trabalho das cuidadoras.

Não obstante, acredito que essa separação é fundamental, uma vez que os conteúdos dessas narrativas indicam um grau diferente de profissionalização do trabalho do cuidado, de 
modo que a primeira narrativa corresponde a um grau baixo de profissionalização, a segunda a um grau intermediário e a terceira a um grau avançado.

Por profissionalização me refiro aos diferentes processos que têm como efeitos conferir mais autonomia e mais controle aos membros de uma determinada ocupação profissional com referência aos conteúdos e aos aspectos técnicos do trabalho. No caso das cuidadoras, a profissionalização é caudatária, prioritariamente, dos cursos de formação de cuidadores de idosos. A distribuição, duração e preço desses cursos variam bastante, bem como a adesão a eles, já que a participação nos cursos não é condição indispensável para exercer a ocupação de cuidadora de idosos. O que esses cursos têm em comum é o efeito de produção de conteúdos estandardizados e formalizados sobre o trabalho e seus procedimentos. Os conteúdos aprendidos nos cursos ultrapassam o saber técnico e discorrem também sobre como deve ser a relação entre cuidadora e idoso cuidado.

\section{As diferentes modulações nos relatos das cuidadoras}

O primeiro relato faz claramente alusão ao cuidado familiar, na medida em que se evoca um fictício laço de parentesco entre cuidadora e idosa cuidada. Esse seria o caso máximo da recriação do cuidado profissional enquanto derivação do cuidado realizado pelas mulheres na família e aparece especialmente na fala das cuidadoras mais velhas. Elas em geral falam com orgulho dos modos como eram chamadas pelos idosos de quem cuidavam, como se os vocativos fossem símbolo de seu bom trabalho.

Mencionar o laço de parentesco, nesse caso, ao mesmo tempo explica e justifica o trabalho das cuidadoras. Movidas pela noção de amor familiar, e mais do que isso, pelos vínculos de reciprocidade e solidariedade que são destinados àqueles que fazem parte da família ${ }^{7}$, essas mulheres aceitam performar o trabalho sujo (dirty work) que constitui parte significativa do trabalho de cuidado, passam a aceitar, assim, as 'artes' dos idosos de quem cuidam.

Dirty work é um termo desenvolvido por Everett Hughes (1993 [1962]) e que qualifica trabalhos cujas atividades consistem em lidar com questões que a sociedade, de modo geral, não sabe ou não quer lidar, pois são moralmente difíceis. O termo foi inicialmente desenvolvido para tratar do trabalho dos alemães em campos de concentração, mas entendo que ele pode ser usado para analisar uma diversidade de trabalhos e ocupações, na medida em que auxilia na compreensão dos mecanismos de distribuição social das práticas moralmente condenáveis ou desvalorizadas.

Para Julia Twigg (2000), o trabalho de cuidado exige que se lide com as impurezas corporais, o que envolve também manejar a sujeira e o nojo. Ter que manipular impurezas envolve sempre o risco de contaminação - seja ela física ou moral. O que importa, nesse caso, é que há pessoas - em geral mulheres, e entre as mulheres, apenas algumas mulheres - mais sujeitas a essas contaminações, pessoas que lidam com o que muitos não gostariam de lidar e dizem não conseguir lidar.

Para essas cuidadoras cuja conexão afetiva desenvolvida com os idosos de quem cuidam é tratada como algo bastante significativo em suas vidas, o dirty work é menos tabu do que para as outras cuidadoras. É como se o laço afetivo atuasse contra o sentido de transgressão atribuído ao cruzamento das fronteiras corporais, permitindo a naturalidade da atuação sobre o corpo do outro. Desse modo, este laço - cristalizado no imperativo do amor e do carinho - opera para essas cuidadoras enquanto uma espécie de propulsor do cuidado, na medida mesma em que é a condição que justifica e explica o trabalho de cuidado, como foi exposto acima.

O que define esse tipo de relato é justamente o apagamento de fronteiras, na medida em que se valoriza a aproximação emocional e física entre cuidadora e idoso e que esse passa a ser simbolizado enquanto alguém a quem se dá tudo de si e, em troca, se recebe afeto e admiração.

O segundo relato evoca o amor ao próximo como fator que orienta o trabalho. Aqui, há certo distanciamento em relação aos modelos de cuidado familiar, ou, visto de outro modo, uma ampliação desse modelo, uma vez que a ideia que o ordena moralmente é a de que todos fariam parte de uma mesma família ou comunidade e que, por isso, deveriam ser tratados com carinho e respeito. Há, aí, a exaltação de um tipo de amor que decorre da valorização da humanidade e que por isso se estende, ao menos idealmente, a todos os membros dela.

Esse tipo de relato é especialmente recorrente entre cuidadoras religiosas, em especial católicas e evangélicas. É comum que essas cuidadoras mencionem que optam por não saber ou não levar em consideração o passado dos idosos de quem cuidam, de modo que possam conferir a eles um cuidado não marcado por julgamentos sobre suas vidas pregressas. Seu trabalho é animado, assim, pelo princípio cristão da absolvição e da misericórdia e investido dos valores de amor ao próximo e do sacrifício.

A despeito do relativo afastamento em relação ao cuidado baseado em um modelo familiar e generificado, o que explica que os poucos homens cuidadores que pude entrevistar se aproximem, em suas falas, deste relato e do último, percebe-se que, ainda assim, este tipo de relato está alicerçado sobre o fundamento do amor e é forte sua relação com a abnegação e o altruísmo.

\footnotetext{
${ }_{7}$ Ou que constituem o ideal de como devem ser as trocas e prestações de dons na família.
} 
O terceiro relato representa um maior afastamento em relação aos modelos familiares que orientam o cuidado. Aqui, o amor não diz respeito, necessariamente, ao estabelecimento de vínculos emocionais com o idoso, mas sim, à aplicação de técnicas e saberes que visam ao seu bem-estar. Essa narrativa articula o saber especializado, profissionalizado e o gabarito moral e emocional, generificado, que prevê a reciprocidade e a solidariedade para com o outro.

Embora essas cuidadoras experimentem em seu dia a dia de trabalho o imperativo do amor enquanto princípio organizador de cuidado, elas o fazem se afastando, ainda que de maneira limitada, dos modelos de reciprocidade e solidariedade próprios ao cuidado familiar. Desse modo, é como se elas buscassem estrategicamente assegurar sua posição no mercado de trabalho remunerado através da renúncia dos preceitos tidos como próprios às mulheres. São elas que abraçam com mais convicção o modelo de profissionalização do cuidado que é difundido por empresas como a em que fiz minha pesquisa, ainda que esse modelo seja parcialmente difundido e que seja também parcial em seus conteúdos, ou seja, não neutraliza o gênero enquanto marcador do trabalho e, pelo contrário, por vezes se vale de argumentos que em muito lembram o cuidado familiar, conforme pode ser visto na fala mencionada acima, da diretora da empresa onde realizei minha pesquisa.

Para essas cuidadoras, o cuidado constitui mais uma técnica do que um dom ou um savoirfaire indiferenciado e advindo de sua socialização familiar. Assim, não basta ser mulher, é necessário que elas se especializem e se qualifiquem, mediante cursos que em geral são oferecidos pela própria empresa, além de que assumam uma postura profissional, isto é, entre outras coisas, que se distanciem da intimidade da família.

Ou seja, a estratégia utilizada pelas cuidadoras mais profissionalizadas em seu trabalho não é a da valorização de uma suposta e específica subjetividade feminina, e sim, a busca pela neutralização e pelo distanciamento dos modos idealizados pelos quais a conduta feminina é pensada.

Não por acaso, essas cuidadoras enfatizam o controle dos sentimentos enquanto componente fundamental de seu trabalho. Isto é, elas entendem que, ainda que as emoções e afetos sejam parte do seu trabalho, eles precisam ser manejados a fim de que não interfiram em sua postura profissional, como fica claro neste relato:

Às vezes quando você vê, você gosta do seu paciente igual você gosta de alguém da sua família. Então tem que saber separar as coisas. A gente tem que manter nosso lugar profissional, porque a gente não é da família dele. A gente é um profissional. A gente pode gostar dele, no que for, mas tipo assim, dentro da casa do paciente, até assim no meio dos familiares dele a gente tem que se pôr como profissional. Mas gostar é uma coisa inevitóvel. (Cuidadora, 21 anos).

Desse modo, essas cuidadoras elaboram estratégias de distanciamento em relação aos idosos: evitam tratá-los por termos que lembrem uma relação familiar e optam por não emitir opinião em assuntos que julgam ser da alçada da família (como frequência de visitas dos parentes dos idosos de quem cuidam ou empréstimo de dinheiro dos idosos a familiares). Poder-se-ia dizer que, para se aproximar do polo da troca mercantil, buscam - ainda que sempre limitadamente mostrar certo afastamento em relação aos sujeitos cuidados ${ }^{8}$.

Para as cuidadoras mais profissionalizadas, as emoções e sentimentos estão sempre em jogo, sempre em disputa. E, na maioria das vezes, ocultá-los, ou conscientemente buscar separarse de papéis mais próximos da família, em prol da adoção de uma postura profissionalizada, formal e movida pela ética da imparcialidade representa uma espécie de proteção das mesmas contra as dificuldades do trabalho.

Optar pela postura profissional significa criar uma barreira - e ao mesmo tempo uma alternativa - ao sacrifício e ao altruísmo incondicionais associados à figura da mulher na família. Aqui, a cuidadora estrategicamente decide refrear a conexão emocional com o idoso, em exercícios cotidianos e práticos que têm como resultado potencial lhe garantir distanciamento e reflexividade em relação ao idoso e sua família, lhe possibilitando ter, por exemplo, menos sofrimento em caso de morte do idoso, ou melhores chances de negociação frente a solicitações e cobranças por parte da família, ou até mesmo maior valorização do seu trabalho.

Viviana Zelizer (2012) argumenta, na mesma direção, que o sentimento de amor das cuidadoras pode desencadear conflitos e tensões, especialmente no que se refere à dificuldade de negociar o número de horas trabalhadas, o salário e as folgas. Entendo, portanto, que o controle dos sentimentos pode ser importante na minimização desses conflitos e tensões.

Uma vez que a via dos afetos e emoções muitas vezes se traduz como a via dos favores, da desequilibrada troca de dons, dos pedidos que não se negam por apreço ou consideração, dos préstimos e dos abusos, a via da profissionalização parece a mais adequada para essas mulheres,

${ }^{8}$ Não por acaso, Chris Gregory (1982, p. 42) trata da dependência recíproca nas transações próprias às sociedades clânicas em termos de "kinship distance". Ora, tal como ocorre neste contexto, no cuidado remunerado a menção à família é justamente o que marca os graus de proximidade com a troca-dádiva. 
conforme verifiquei durante a pesquisa.

Alexandre Barbosa Fraga (2013, p. 160-161) comenta que é comum que Sindicatos de Empregadas Domésticas valorizem e procurem incentivar a criação de relações de trabalho mais racionais e contratuais, uma vez que, quando as relações trabalhistas se confundem com as relações familiares, os direitos como trabalhadora são mais facilmente desrespeitados.

O que se busca, no caso das cuidadoras e no caso das empregadas domésticas pesquisadas por Fraga, é a saída do modelo de prestações totais baseado na dádiva-troca, em nome de uma suposta maior justiça da troca mercantil. A escolha dessa via imprescinde, no entanto, como fica claro no relato da cuidadora, de uma incansável mediação dos sentimentos e emoções, que aqui se traduz em estabelecimento de limites, na criação de fronteiras entre o que compete ou não à cuidadora e entre o que lhe é permitido ou não ouvir, sentir e dizer; ou seja, o estabelecimento de limites se dá por um processo de esterilização das relações sociais entre cuidadoras e idosos: essas devem se apartar, tanto quanto possível, embora nunca totalmente, da carga moral e emocional relacionada ao sistema de prestações totais e, mais especificamente, às reciprocidades históricas das mulheres.

\section{O sacrifício}

Mas eu sempre tive essa vocação, eu sempre gostei. Que como eu não tive avó de nenhuma das duas partes, eu tenho isso comigo. Então, eu amo, eu faço de coração, eu não faço por fazer. Eu não faço só por causa de dinheiro. (Cuidadora, 51 anos).

No célebre texto Ensaio sobre a natureza e a função do sacrifício, Henri Hubert e Marcel Mauss (1981 [1898]) entendem o sacrifício como uma espécie de dádiva, seria ela a forma mais potente de dom: a dádiva de si. O sacrifício requer abnegação, um tipo de doação do eu que por vezes é imposto a partir do estabelecimento de caráter ou princípio de obrigação. É útil pensar, no caso do trabalho de cuidado, que tipo de obrigações asseguram sua realização.

O sacrifício que é resultante do imperativo da obrigação é ele mesmo tornado símbolo e garantia do bom trabalho, como fica claro no relato da diretora da MaisCuidador. Assim, o sacrifício é mercantilizado e valorizado pela empresa, sob a forma de uma disposição natural e irremediável para o cuidado, como uma espécie de altruísmo quase ilimitado que seria comum às mulheres, ou a algumas mulheres, como será mostrado abaixo.

Para as cuidadoras, a plenitude do sacrifício exigiria a renegação do dinheiro. Ainda que não o façam em sua prática profissional, há por parte das mesmas uma moralização generalizada do cuidado feito 'apenas' em troca de ganhos materiais, como pode ser visto no relato mencionado no início da seção.

Há nesse relato a valorização ainda que oculta da noção de sacrifício. É o sacrifício feito em nome do amor - demanda moral e emocional do trabalho, mas também demanda proveniente da naturalização dos papéis femininos na família - que legitima o trabalho de cuidado. Sem amor não há sacrifício e só resta o dinheiro. Este é tratado como coisa profana, que tem o potencial de macular o verdadeiro sentido do cuidado?. Entre as cuidadoras menos profissionalizadas, é comum que relatem que precisam do dinheiro oferecido em troca de seus serviços, mas que se pudessem e tivessem condições, não cobrariam salário. Essa recusa - mesmo que no plano do ideal - ao dinheiro representa uma das tensões entre sistema-mercantil e sistema-dádiva do cuidado: aqui, o objetivo último da cuidadora não é maximizar seus lucros; ao contrário, ela valoriza os laços pessoais construídos com o idoso e fala de seu trabalho como uma vocação.

É importante considerar também que o princípio de obrigação do cuidado se articula com determinantes macroestruturais na medida em que operam, enquanto forças para a realização do cuidado - ou para sua delegação -, distinções de gênero, de raça e de classe. Isto permite concluir que existe um modo sistemático e não ocasional pelo qual o trabalho de cuidado é alocado socialmente (Evelyn Nakano GLENN, 2010). Em outros termos, o sentido de obrigação atribuído ao cuidado recai mais pesadamente sobre alguns em detrimento de outros, os quais ou se eximem do mesmo ou têm poderes para delegar as tarefas de cuidado a outrem. Assim, lançar luz sobre os sujeitos do cuidado permite pensar como a organização e repartição do cuidado reflete traços sociais e políticos e pressupõe também a existência de uma concepção moral de responsabilidade que atinge diferencialmente os sujeitos (Patricia PAPERMAN; Pascale MOLINIER, 2013). Aqui, penso essa responsabilidade em termos de demandas morais e emocionais do trabalho, considerando a dimensão estratificada de sua distribuição. Ou seja, como a responsabilidade é interpretada e distribuída em termos generificados, racializados e de classe. Nesse sentido, me valho da proposição de Joan TRONTO (1993), para quem o cuidado é associado à subalternidade e reproduz padrões de subordinação.

\footnotetext{
${ }^{9}$ Nancy Folbre e Erik Olin Wright (2012, p. 2) apontam que, no cuidado, o senso de obrigação moral é mais forte e a motivação salarial mais fraca que em outros tipos de trabalho. No meu contexto específico de pesquisa, esse senso de obrigação moral é entendido pelas cuidadoras em termo de sacrifício e amor.
} 
Desse modo, percebe-se que a organização social e sexual do trabalho é determinante fundamental para a distribuição do sacrifício requerido pelo cuidado. Isto é, importa compreender que o princípio da obrigação que anima o cuidado não é democraticamente distribuído e fatores socioestruturais o ordenam.

Na pesquisa, verificou-se que quase $58 \%$ das cuidadoras se definiam como pardas ou pretas e $60 \%$ das cuidadoras possuíam renda familiar inferior a três salários mínimos. É difícil obter dados oficiais sobre a composição sociodemográfica das cuidadoras de idosos, uma vez que muitas vezes sua ocupação é tabulada juntamente com outros profissionais do cuidado como babás, por exemplo, como argumentam Jurema Brites e Felícia Picanço (2014). Além disso, há uma tendência das cuidadoras que trabalham em residências de descrever suas atividades como serviço doméstico, como aponta Guimarães (2016). Assim, embora o perfil das cuidadoras que constituem objeto desta pesquisa não tenha relevância estatística, dado o tamanho da amostra, ele é aqui mencionado a título de ilustração e de qualificação dos dados.

\section{A paciência}

Quando tem Alzheimer, te pergunta 10, 20 vezes a mesma coisa. Você tem que ter paciência. No caso deles, eles esquecem. E você tem que ter paciência sempre. Quando ele é agressivo, você tem que ter paciência, você não vai gritar também junto com ele. Então a gente tem que ter paciência. (Cuidadora Amanda)

Eu acho que paciência é sempre. Você tem que tá sempre paciente com eles, até porque eles tão começando a ficar naquela fase de repetir toda hora a mesma coisa, eles tão na fase né. E toda hora quer alguma coisa e tem hora que a gente não tem tempo pra dar porque a gente... No meu, eu faço tudo [se ocupa dos serviços domésticos porque a idosa mora sozinha]. Então tem horas que eu não posso parar de fazer o que eu tô fazendo e dar atenção porque [ela] chama a gente às vezes por nada. Então a gente tem que ter paciência. [imita como fala com a idosa] "Espera um pouquinho, eu já tô indo". A dona Ciça chama bastante a gente. Então eu acho que tem que ter paciência. Até porque eles gostam muito da gente perto deles. Eles querem a gente o tempo todo em cima deles e eu acho que também não pode ser assim, então tem que ter paciência. [imita novamente como fala com a idosa] "Aguarda um pouquinho, já vou". Toda hora tem que tá repetindo a mesma coisa. (Cuidadora Rita)

Os dois relatos apresentam duas feições distintas do modo como as cuidadoras operacionalizam a paciência que lhes é demandada no trabalho. No primeiro trecho, a paciência se relaciona com a concessão, com a renúncia e, em última instância, com o sacrifício. A cuidadora se sente na obrigação de aceitar tanto as repetições quanto a agressividade do idoso. Também é comum que ela justifique essa agressividade ao tomá-la como efeito da ausência da família do idoso, ou da perda repentina de autonomia do mesmo. Essas situações teriam como efeito o aumento da irritabilidade do idoso, e entende-se que é parte do trabalho da cuidadora compreender e curvar-se diante desse tipo de comportamento. É interessante notar como, por vezes, os ideais de feminilidade carregam conotações de docilidade e tolerância para as trabalhadoras (MOHANTY, 1997). Nesse sentido, no meu contexto específico de pesquisa, a paciência opera como instrumento de controle do trabalho.

O segundo relato traz uma mudança sutil - porém significativa - em relação ao primeiro. Embora a cuidadora mencione, como faz a primeira, que os idosos têm costume de repetir as coisas, esta enfatiza seu caráter de negociante - em oposição ao papel de concessora daquela - no que diz respeito ao atendimento das demandas do idoso. Ou seja, para ela, a paciência se relaciona mais com a necessidade de constante e incansavelmente impor limites às expectativas do idoso e através do diálogo ajustá-las de modo a conseguir uma relação mais satisfatória para ambas as partes. Essa mediação também é feita com a família, especialmente nos casos em que o idoso já não se expressa muito.

A postura da segunda é símbolo do maior controle que a mesma tem em relação aos processos do trabalho e ao modo como entende seu próprio trabalho, isto é, ela compreende que parte do seu trabalho é impor limites nas interações diárias. Ou seja, representa uma recusa, ainda que limitada, ao modelo de dádivas-sacrifício do cuidado familiar generificado e a aproximação com um modelo de cuidado mais profissionalizado e sujeito ao controle, não mais do empregador, mas da própria cuidadora.

\section{Considerações finais}

É importante ressaltar que um dos esforços deste texto consistiu em buscar compreender o mercado de trabalho do cuidado tomando como central a noção de embeddedness, ou seja, este não foi visto como uma organização autorregulada pelas leis neoclássicas da economia, mas como uma instituição situada cultural, histórica e estruturalmente. Em alguma medida é essa perspectiva que legitima minha escolha em conferir destaque, no que toca à construção 
argumentativa, ao modelo do trabalho de cuidado não remunerado, que é pensado a partir de suas tensões, inter-relações e continuidades com o mercado de trabalho do cuidado pago.

Assim, iniciei o texto discorrendo sobre como a ideia de cuidado familiar e de reciprocidades intergeracionais representam um cenário idealizado que informa as demandas morais e emocionais do trabalho das cuidadoras. Posteriormente, mostrei como a ideia de profissionalização imprescinde de um afastamento em relação a modelos de cuidado familiar, o que se percebe, por exemplo, na ênfase dada ao distanciamento - inclusive afetivo - na relação entre cuidadora e idoso.

De fato, a formação das cuidadoras e o modo como seu trabalho é agenciado muito tem a ver com a relação entre mercado e reciprocidade, com a imagem idealizada do cuidado familiar e, mais que isso, com a especificidade dos sujeitos que performam o cuidado: as mulheres.

Verificou-se que a moralidade histórica feminina, aqui entendida em termos de reciprocidades e solidariedades familiares, traveste-se de empecilho à valorização do trabalho das cuidadoras e opera como mecanismo mantenedor de subordinações. É justamente o afastamento dessa subjetividade que se converte em estratégia de resistência contra determinadas formas de exploração no trabalho de cuidado.

Em outras palavras, a mercantilização da troca, num sentido amplo ${ }^{10}$, e do cuidado, em particular, não aparecem total e necessariamente como monstros a serem eliminados, ou como a raiz de todos os problemas morais, sociais e previdenciários. Aqui, tratando do cuidado, me refiro especificamente: a) ao argumento de que o cuidado remunerado é menos nobre; b) à discussão sobre as redes migratórias de cuidado e seus efeitos sobre a distribuição do cuidado e; c) à estatização ou não dos serviços de cuidado, e às diferentes soluções (públicas, privadas ou caritativas) encontradas pelos países para lidar com a crescente demanda por cuidado de idosos conjugada a uma menor possibilidade de realização do mesmo no seio da família.

Ou seja, as tensões apontadas aqui não se resolvem com o retorno do cuidado para o provimento não remunerado. De fato, como Nancy Fraser (2014, p. 544) bem coloca, em sua crítica a Karl Polanyi, injustiças como servidão, escravismo e patriarcado dependem justamente de que trabalho, terra e dinheiro sejam vistos como não mercadorias. Ou seja, é preciso estar atento também às desigualdades, injustiças e dominações que têm lugar na "vida social", ao invés de apenas mirar como alvo da crítica o mundo do mercado, e mais do que isso, pensar como a mercantilização pode ensejar emancipação - ainda que de forma limitada e incompleta -, na medida em que enfraquece os "suportes tradicionais da dominação" (FRASER, 2014, p. 548).

Para alguns, a exploração - capitalista - é uma saída melhor do que a dominação feudal, patriarcal, escravocrata. Daí a constatação de que a mercantilização pode ser emancipatória. Isso implica considerar que, para as mulheres, ainda que seu trabalho seja apropriado pelo mercado em condições de baixa remuneração e pouco reconhecimento social, sua condição parece ser mais vantajosa do que a daquelas que têm seu trabalho expropriado gratuitamente - como coloca Christine Delphy (1984) - pelo simples fato de serem mulheres ou esposas.

É preciso considerar, especialmente, a desigualdade de gênero que, conforme apontado por várias feministas, tem a capacidade de se transferir, repetidamente, da esfera familiar - aqui entendida como a esfera das reciprocidades - para a esfera do mercado, e vice-versa, sendo por isso necessário também atentar para as diferentes nuanças e potenciais recuos das desigualdades de gênero nesta transição. Nesse sentido, a análise das demandas morais e emocionais do trabalho pode fornecer uma boa pista - ou uma boa métrica - para capturar como a desigualdade de gênero é ao mesmo tempo traduzida, transportada e transformada quando da passagem do trabalho não pago para o trabalho pago.

\section{Referências}

BADGET, Lee; FOLBRE, Nancy. "Assigning care: Gender norms and economic outcomes". International Labour Review, v. 138, n. 3, p. $311-326,1999$.

BRITES, Jurema; PICANÇO, Felícia. "O emprego doméstico no Brasil em números, tensões e contradições: alguns achados de pesquisa". Revista Latino-americana de Estudos do Trabalho, ano 19, n. 31, p. 131-158, 2014.

BOURDIEU, Pierre. Meditações Pascalianas. Rio de Janeiro: Bertrand Brasil, 2007.

CROMPTON, Rosemary. Employment and the Family: The Reconfiguration of Work and Family Life in Contemporary Societies. Cambridge: University Press, 2006.

DELPHY, Christine. Close to Home: A Materialist Analysis of Women's Oppression. London: Hutchinson, 1984.

10 i.e. sua maior correspondência ao modelo formalista da economia. 
DEVREUX, Anne-Marie. "A teoria das relações sociais de sexo: um quadro de análise sobre a dominação masculina". Sociedade e Estado, Brasília, v. 20, n. 3, p. 561-584, dez. 2005.

FOLBRE, Nancy; WRIGHT, Erik Olin. "Defining Care". In: FOLBRE, Nancy (Ed.). For Love and Money: Care provision in the United States. New York: Russel Sage Foundation, 2012. p. 1-20.

FRAGA, Alexandre Barbosa. De empregada a diarista: as novas configurações do trabalho doméstico remunerado. Rio de Janeiro: Editora Multifoco, 2013.

FRASER, Nancy. "Can society be commodities all the way down? Post-Polanyian reflections on capitalist crisis". Economy and Society, v. 43, n. 4, p. 541-558, 2014.

GLENN, Evelyn Nakano. Forced to care: Coercion and caregiving in America. Cambridge: Harvard University Press, 2010.

GOULDNER, Alvin W. "The Norm of Reciprocity: A Preliminary Statement". American Sociological Review, v. 25, n. 02, p. 161-178, 1960.

GREGORY, Chris A. Gifts and Commodities. London: Academic Press, 1982.

GUIMARÃES, Nadya Araujo. "A sociologia dos mercados de trabalho, ontem e hoje". Novos Estudos -CEBRAP, São Paulo, n. 85, p. 151-170, 2009.

GUIMARÃES, Nadya Araujo. "O que muda quando se expande o assalariamento (e em que 0 debate da Sociologia pode nos ajudar a compreendê-lo)?". Dados, Rio de Janeiro, v. 54, n. 4, p. 533-568, 2011.

GUIMARÃES, Nadya Araujo. "Casa e mercado, amor e trabalho, natureza e profissão: controvérsias sobre o processo de mercantilização do trabalho de cuidado". Cadernos Pagu, Campinas, n. 46, p. 59-77, abr. 2016.

HIRATA, Helena; KERGOAT, Danièle. "Novas configurações da divisão sexual do trabalho". Cadernos de Pesquisa, São Paulo, v. 37, n. 132, p. 595-609, dez. 2007.

HOCHSCHILD, Arlie. The managed heart: Commercialization of human feeling. Berkeley: University of California Press, 2003 [1983].

HOCHSCHILD, Arlie. "Éthique du care et capitalisme émotionnel". In: PAPERMAN, Patricia; MOLINIER, Pascale (Dir.). Contre l'indifférence des privilégiés: À quoi sert le care. Paris: Payot, 2013. p. 69-97.

HUBERT, Henri; MAUSS, Marcel. "Ensaio Sobre a Natureza e a Função do Sacrifício". In: MAUSS, Marcel. Ensaios de Sociologia. São Paulo: Perspectiva, 1981 [1898]. p. 141-227.

HUGHES, Everett. "Good people and dirty work". In: HUGHES, Everett. The Sociological Eye: Selected Papers. 2. ed. New Brunswick: Transaction Publishers, 1993 [1962]. p. 87-97.

MAUSS, Marcel. "Ensaio sobre a dádiva. Forma e razão da troca nas sociedades arcaicas". In: MAUSS, Marcel. Sociologia e Antropologia. São Paulo: Cosac \& Naify. 2003 [1925]. p. 183-314.

MOHANTY, Chandra. "Women Workers and Capitalist Scripts: Ideologies of domination, common interests, and the politics of solidarity". In: ALEXANDER, M. Jacqui; MOHANTY, Chandra (Eds.). Feminist Genealogies, Colonial Legacies, Democratic Futures. New York: Routledge, 1997. p. 3-29.

ORTNER, Sherry B. "Está a mulher para o homem assim como a natureza para a cultura?". In: MICHELLE, Zimbalist Rosaldo; LAMPHERE, Louise (Orgs.). A mulher a cultura a sociedade. Rio de Janeiro: Paz e Terra, 1979. p. 95-120.

PAPERMAN, Patricia; MOLINIER, Pascale. "Présentation: Désenclaver le care?". In: PAPERMAN, Patricia; MOLINIER, Pascale (Dir.). Contre l'indifférence des privilégiés: À quoi sert le care. Paris: Payot, 2013. p. 7-34.

POLANYI, Karl. "The economy as instituted process." In: POLANYI, Karl; ARENSBERG, Conrad M.; PEARSON, Harry W. (Eds.). Trade and Market in the Early Empires: Economies in History and Theory. Glencoe, Illinois: The Free Press, 1957. p. 243-270.

RUBIN, Gayle. O tráfico de mulheres: notas sobre a "economia política do sexo". Recife: SOS Corpo, 1993. 
SABOURIN, Eric. "Marcel Mauss: da dádiva à questão da reciprocidade". Revista Brasileira de Ciências Sociais, São Paulo, v. 23, n. 66, p. 131-138, fev. 2008.

SINGLY, François de. Sociologia da família contemporânea. Tradução de Clarice Ehlers Peixoto. Rio de Janeiro: Editora FGV, 2007.

SPIVAK, Gayatri Chakravorty. "The Politics of Interpretation”. Critical Inquiry, v. 9, n. 1, p. 259-278, 1982.

STRATHERN, Marilyn. O gênero da dádiva: problemas com as mulheres e problemas com a sociedade na Melanésia. Campinas: Editora da Unicamp, 2006.

TRONTO, Joan. Moral Boundaries: A Political Argument for an Ethic of Care. New York: Routledge, 1993.

TWIGG, Julia. "Carework as a form of bodywork". Ageing and Society, v. 20, n. 04, p. 389-41 1, 2000.

WASSER, Nicolas. The Promise of Diversity: How Brazilian Brand Capitalism Affects Precarious Identities and Work. Bielefeld: Transcript, 2017.

ZELIZER, Viviana. "A Economia do care". In: HIRATA, Helena; GUIMARÃES, Nadya (Orgs.). Cuidado e Cuidadoras: as várias faces do trabalho de care. São Paulo: Editora Atlas, 2012. p. 15-28.

Anna Bárbara Araujo (iD 0000-0002-2792-9931

Doutoranda pelo Programa de Pós-Graduação em Sociologia e Antropologia (março de 2018), realiza pesquisas na interface entre trabalho e gênero, e mais especificamente sobre cuidado de idosos.

Universidade Federal do Rio de Janeiro, Programa de Pós-Graduação em Sociologia e Antropologia, Largo de São Francisco de Paula, 1, sala 420, Centro

20051-070 - Rio de Janeiro - RJ, Brasil

(21) 2224-8965 - ppgsa.ifcs@gmail.com

annabarbaraaraujo@gmail.com

COMO CITAR ESSE ARTIGO DE ACORDO COM AS NORMAS DA REVISTA

ARAUJO, Anna Bárbara. "Gênero, reciprocidade e mercado no cuidado de idosos". Revista Estudos Feministas, Florianópolis, v. 27, n. 1, e45553, 2019.

CONTRIBUIÇÃO DE AUTORIA

Não se aplica

FINANCIAMENTO

A pesquisa contou com o apoio da CAPES, sob a forma de uma bolsa de mestrado, vigente entre abril de 2013 e março de 2015.

CONSENTIMENTO DE USO DE IMAGEM

Não se aplica

APROVAÇÃO DE COMITÊ DE ÉTICA EM PESQUISA

Não se aplica

CONFLITO DE INTERESSES

Não se aplica 


\section{LICENÇA DE USO}

Este artigo está licenciado sob a Licença Creative Commons CC-BY. Com essa licença você pode compartilhar, adaptar, criar para qualquer fim, desde que atribua a autoria da obra.

\section{HISTÓRICO}

Recebido em 12/07/16

Reapresentado em 23/1 1/2017

Aprovado em 17/04/2018 